Subscriber access provided by Caltech Library

\title{
Communication
}

\section{High Broadband Light Transmission for Solar Fuels Production Using Dielectric Optical Waveguides in TiO Nanocone Arrays}

Sisir Yalamanchili, Erik Verlage, Wen-Hui Cheng, Katherine T. Fountaine, Philip R. Jahelka, Paul A. Kempler, Rebecca Saive, Nathan S. Lewis, and Harry A Atwater

Nano Lett., Just Accepted Manuscript • DOI: 10.1021/acs.nanolett.9b04225 • Publication Date (Web): 10 Dec 2019

Downloaded from pubs.acs.org on December 11, 2019

\section{Just Accepted}

"Just Accepted" manuscripts have been peer-reviewed and accepted for publication. They are posted online prior to technical editing, formatting for publication and author proofing. The American Chemical Society provides "Just Accepted" as a service to the research community to expedite the dissemination of scientific material as soon as possible after acceptance. "Just Accepted" manuscripts appear in full in PDF format accompanied by an HTML abstract. "Just Accepted" manuscripts have been fully peer reviewed, but should not be considered the official version of record. They are citable by the Digital Object Identifier (DOI@). "Just Accepted" is an optional service offered to authors. Therefore, the "Just Accepted" Web site may not include all articles that will be published in the journal. After a manuscript is technically edited and formatted, it will be removed from the "Just Accepted" Web site and published as an ASAP article. Note that technical editing may introduce minor changes to the manuscript text and/or graphics which could affect content, and all legal disclaimers and ethical guidelines that apply to the journal pertain. ACS cannot be held responsible for errors or consequences arising from the use of information contained in these "Just Accepted" manuscripts. 


\section{High Broadband Light Transmission for Solar Fuels Production Using Dielectric Optical Waveguides in $\mathrm{TiO}_{2}$ Nanocone Arrays}

Sisir Yalamanchili ${ }^{1 \dagger}$, Erik Verlage ${ }^{1 \dagger}$, Wen-Hui Cheng $^{1 \dagger}$, Katherine T. Fountaine ${ }^{5}$, Philip R. Jahelka $^{1}$, Paul A. Kempler ${ }^{2}$, Rebecca Saive ${ }^{1}$, Nathan S. Lewis ${ }^{2,4^{*}}$, and Harry A. Atwater ${ }^{1,3 *}$

${ }^{1}$ Division of Engineering and Applied Sciences, California Institute of Technology, Pasadena, CA 91125

${ }^{2}$ Division of Chemistry and Chemical Engineering, California Institute of Technology, Pasadena, CA 91125

${ }^{3}$ Kavli Nanoscience Institute, California Institute of Technology, Pasadena, CA 91125

${ }^{4}$ Beckman Institute, California Institute of Technology, Pasadena, CA 91125

${ }^{5}$ NGNext, Northrop Grumman Aerospace Systems, Redondo Beach, CA 90278

${ }^{\dagger}$ These authors contributed equally

*Corresponding Authors: haa@ caltech.edu, nslewis@ caltech.edu 


\begin{abstract}
We describe the fabrication and use of arrays of $\mathrm{TiO}_{2}$ nanocones to yield high optical transmission into semiconductor photoelectrodes covered with high surface loadings of lightabsorbing electrocatalysts. Covering over $50 \%$ of the surface of a light absorber with an array of high-refractive-index $\mathrm{TiO}_{2}$ nanocones imparted antireflective behavior $(<5 \%$ reflectance) to the surface and allowed $>85 \%$ transmission of broadband light to the underlying Si, even when thick metal contacts or opaque catalyst coatings were deposited on areas of the light-facing surface that were not directly beneath a nanocone. Three-dimensional full-field electromagnetic simulations for the 400 - $1100 \mathrm{~nm}$ spectral range showed that incident broadband illumination couples to multiple waveguide modes in the $\mathrm{TiO}_{2}$ nanocones, reducing interactions of the light with the metal layer. A proof-of-concept experimental demonstration of light-driven water oxidation was performed using a $\mathrm{p}^{+} \mathrm{n}-\mathrm{Si}$ photoanode decorated with an array of $\mathrm{TiO}_{2}$ nanocones additionally having a $\mathrm{Ni}$ catalyst layer electrodeposited onto the areas of the $\mathrm{p}^{+} \mathrm{n}-\mathrm{Si}$ surface left uncovered by the $\mathrm{TiO}_{2}$ nanocones. This photoanode produced a light-limited photocurrent density of $\sim 28 \mathrm{~mA} \mathrm{~cm}{ }^{-2}$ under $100 \mathrm{~mW}$ $\mathrm{cm}^{-2}$ of simulated Air Mass 1.5 illumination, equivalent to the photocurrent density expected for a bare planar Si surface even though $54 \%$ of the front surface of the Si was covered by an $\sim 70 \mathrm{~nm}$ thick Ni metal layer.
\end{abstract}

Keywords: dielectric nanocone, broadband transmission, nanophotonic, optoelectronic, photoelectrochemical, photovoltaic 


\section{Table of contents graphic:}

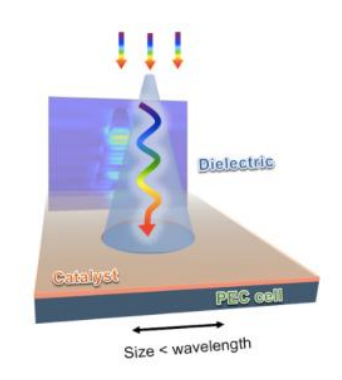

\section{Main Text}

High efficiency conversion of solar energy to electricity or fuels using photovoltaic $(\mathrm{PV})^{1-5}$ or photoelectrochemical (PEC) $)^{6-8}$ cells requires optimization of the broadband absorption of sunlight. Anti-reflective coatings (ARCs) ${ }^{9}$, surface textures, ${ }^{10-13}$ and high-index light-trapping structures $^{14,15}$ are among the many strategies that have been shown to increase broadband absorption relative to unmodified planar light absorbers. PECs and multijunction PVs generally require front contacts and/or electrocatalytic films that substantially reflect or absorb light, thereby reducing their photocurrent densities. ${ }^{16}$ In integrated PECs used to effect solar-driven water splitting or $\mathrm{CO}_{2}$ reduction, ${ }^{17-19}$ the front contact is made to an electrolyte, and a catalyst located in the optical path increases the efficiency of the cell by reducing the kinetic barrier for the electrochemical half-reaction occurring at the top contact. Depending on the orientation of the design, as well as the chemical inputs and desired products, the catalyst may be optically opaque (such as $\mathrm{CoP}$ for water reduction or $\mathrm{Cu}$ for $\mathrm{CO}_{2}$ reduction) or may be electrochromic (such as $\mathrm{NiFeO}_{\mathrm{x}}$ for water oxidation). ${ }^{20}$ Although an all-back-contact design ${ }^{21,22}$ can prevent contact shading losses in crystalline $\mathrm{Si}$ solar cells, such a design is not compatible with all of the solid/liquid interfaces either with integrated PECs for highly efficient fuel production or with multijunction PV device structures. ${ }^{23}$ 
Nanostructuring the semiconductor is one approach that has been developed to enhance broadband absorption. Nanowires, ${ }^{24-26}$ inverted pyramids, ${ }^{27}$ nanodomes,${ }^{28}$ nanoshells, ${ }^{29}$ nanopillars, ${ }^{30,31}$ and nanocones ${ }^{32}$ have been explored for use in many optoelectronic devices. For example, for wavelengths ranging between $400-1100 \mathrm{~nm}$ and angles-of-incidence between $0^{\circ}-$ $50^{\circ}$, Si microcone arrays exhibit nearly perfect angularly and spectrally averaged reflectivity $(<1$ $\%)$ as well as high $(89.1 \%)$ absorption. ${ }^{33}$ Sparse arrays of InP nanocones also exhibit angleinsensitive, near-unity (>90\%), broadband (450-900 nm) optical absorption. ${ }^{34}$ Cones inherently possess a continuous range of radii that provides a range of waveguide modes accessible for coupling with incident light. ${ }^{35}$ Hence, cones are intrinsically favorable structures for enabling enhanced broadband absorption. Moreover, the radius at the base of the cone and the radius of any truncation can be chosen specifically to select a spectral range of interest.

Alternatively, broadband absorption can be enhanced by decorating the light-facing surface of the semiconductor with dielectric nanostructures, such as nanospheres, ${ }^{36}$ that serve as waveguides. This approach requires a high-index dielectric that can be deposited on planar surfaces using scalable methods. For integrated PEC devices, the dielectric also must be stable in the chosen aqueous electrochemical environment. $\mathrm{TiO}_{2}$ has been used in waveguides for near-visible and telecommunication wavelengths, ${ }^{37-42}$ and has a higher index of refraction $(n \sim 2.5)$ than many other dielectric materials commonly used in solar photovoltaic devices, including $\mathrm{SiO}_{2}(n=1.5)$ and $\mathrm{Al}_{2} \mathrm{O}_{3}(n=1.77) . \mathrm{TiO}_{2}$ is relatively inert electrochemically and has a wide band gap that allows transmission of incident solar illumination, and has been utilized extensively as a protective coating in efficient PEC devices. ${ }^{17-19,43-48} \mathrm{TiO}_{2}$ is therefore a promising candidate material for nanostructured waveguides in PEC devices. 
Devices that make use of nanostructured surfaces nevertheless require front contacts, either to a conductor for PVs or to a catalyst for PECs, but the front contact can block light. In devices that require connections between external circuits and nanostructured optical surfaces, front contacts typically are formed by coating the surface with a transparent and conductive material, such as indium tin oxide (ITO). However, efficient integrated PECs for fuel production additionally require catalysts on at least one of the optical surfaces. Very high (> 90\%) absorption and high front-surface conductivity have been demonstrated using both simulation and experiment in a device consisting of $\mathrm{SiN}_{\mathrm{x}}$-coated $\mathrm{Si}$ nanopillars protruding from a crystalline $\mathrm{Si}$ substrate coated with an opaque Au front-side contact that covered $65 \%$ of the Si surface. ${ }^{31}$ Although the selective etching process used in this approach limits its applicability to a few specific interfaces such as $\mathrm{Au} / \mathrm{Si}$, this work shows that nanostructures can direct light around opaque metallic front contacts deposited onto the optical surfaces of PV devices, and suggests a strategy for guiding light around catalyst layers in PECs.

Considered together, the prior work in the areas of antireflective nanostructures and dielectric waveguides underscores the potential value and developmental feasibility of modular antireflective coatings that promote broadband absorption over a spectral range above the photoelectrode bandgap without requiring modification of the underlying semiconductor or contact interfaces. Herein, we combine simulations and proof-of-concept experiments to evaluate and demonstrate light management by an array of $\mathrm{TiO}_{2}$ nanocones placed on the surface of a $\mathrm{p}^{+} \mathrm{n}-\mathrm{Si}$ photoanode with a metallic Ni contact covering the exposed Si surface.

Figure 1 shows schematics for three device configurations that were compared using simulations, to understand the optical properties of $\mathrm{TiO}_{2}$ nanocones. In the first configuration 
(Figure 1a), $\mathrm{TiO}_{2}$ nanocones with a height of $2300 \mathrm{~nm}$ and a base radius of $250 \mathrm{~nm}$ were placed on the Si substrate in a 2D hexagonal array with a $700 \mathrm{~nm}$ pitch. This arrangement left $54 \%$ of the $\mathrm{Si}$ surface uncovered by $\mathrm{TiO}_{2}$ nanocones. In the second configuration (Figure 1b), $50 \mathrm{~nm}$ of Ni covered the area of Si that remained exposed in the first configuration. The third configuration (Figure 1c) was the same as the second, but the $\mathrm{TiO}_{2}$ nanocones were removed, leaving a hexagonal array of circles of exposed $\mathrm{Si}$ in the Ni layer.
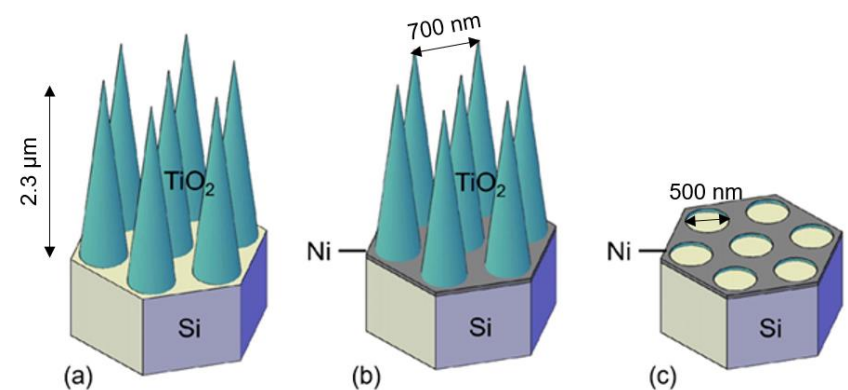

Figure 1: Schematics of the three configurations that were simulated. (a) $\mathrm{TiO}_{2}$ nanocones on $\mathrm{Si}$ substrate; (b) Ni between the $\mathrm{TiO}_{2}$ nanocones on Si substrate; (c) Ni hole arrays on Si substrate.

Figure 2 compares the simulated transmission, absorption, and reflection spectra for the $\mathrm{TiO}_{2}$ and $\mathrm{Ni}$ components of the three structures, either in air $(\mathrm{n}=1.0)$ or in water $(\mathrm{n}=1.33)$. Figures $2 \mathrm{a}$ and $2 \mathrm{~d}$ show that the $\mathrm{TiO}_{2}$ nanocones neither absorb nor reflect substantially in the 400 $-1100 \mathrm{~nm}$ spectral range, with the nanocones allowing transmission of $97.5 \%$ of the total incident photons in air or $96.9 \%$ in water. The planar $\mathrm{TiO}_{2}$ film simulations, with higher reflection losses, are shown in Figure S1, leading to transmission of $74.7 \%$ in air and $84 \%$ in water. When $50 \mathrm{~nm}$ of Ni was added into the spaces between the nanocones, the simulated transmitted photon flux was reduced to $86.2 \%$ in air or $84.7 \%$ in water (Figures $2 \mathrm{~b}$ and $2 \mathrm{e}$ ). The minima in transmission primarily result from absorption by $\mathrm{Ni}$, and the wavelengths of the minima shift depending on the index of refraction of the surrounding environment. 
When the $\mathrm{TiO}_{2}$ nanocones were removed from the simulation, leaving just the hexagonal array of circular holes in a $50 \mathrm{~nm}$ layer of $\mathrm{Ni}$ that covered $54 \%$ of the optical plane, the transmitted photon fluxes were reduced to $23.3 \%$ in air or $24.8 \%$ in water, with reflection and parasitic absorption accounting for $\geq 75 \%$ of the optical losses (Figures $2 \mathrm{c}$ and $2 \mathrm{f}$ ). The size and pitch of the holes in the Ni layer were particularly unfavorable for transmission of light through the Ni layer in the absence of the $\mathrm{TiO}_{2}$ cones, because over a large fraction of the incident solar spectrum, the diameter of the holes was less than the wavelength of the incident light. In the specific configuration shown in Figure $1 \mathrm{~b}$, the $\mathrm{TiO}_{2}$ nanocones minimized the interaction between the light and the Ni layer, enabling $>3$ times the amount of light to be transmitted than for the Ni hole array that did not also contain the $\mathrm{TiO}_{2}$ cones. For the $\mathrm{TiO}_{2}$ nanocone array with $\mathrm{Ni}$, the simulated transmission at the minima was $\geq 60 \%$, Figures $2 \mathrm{~b}$ and $2 \mathrm{e}$, whereas for the Ni hole array without $\mathrm{TiO}_{2}$ nanocones, the simulated transmission of was $20-30 \%$, Figures $2 \mathrm{c}$ and $2 \mathrm{f}$. The simulations thus indicated that incident light is expected to couple efficiently to the $\mathrm{TiO}_{2}$ nanocones that guide the light around the Ni layer. 

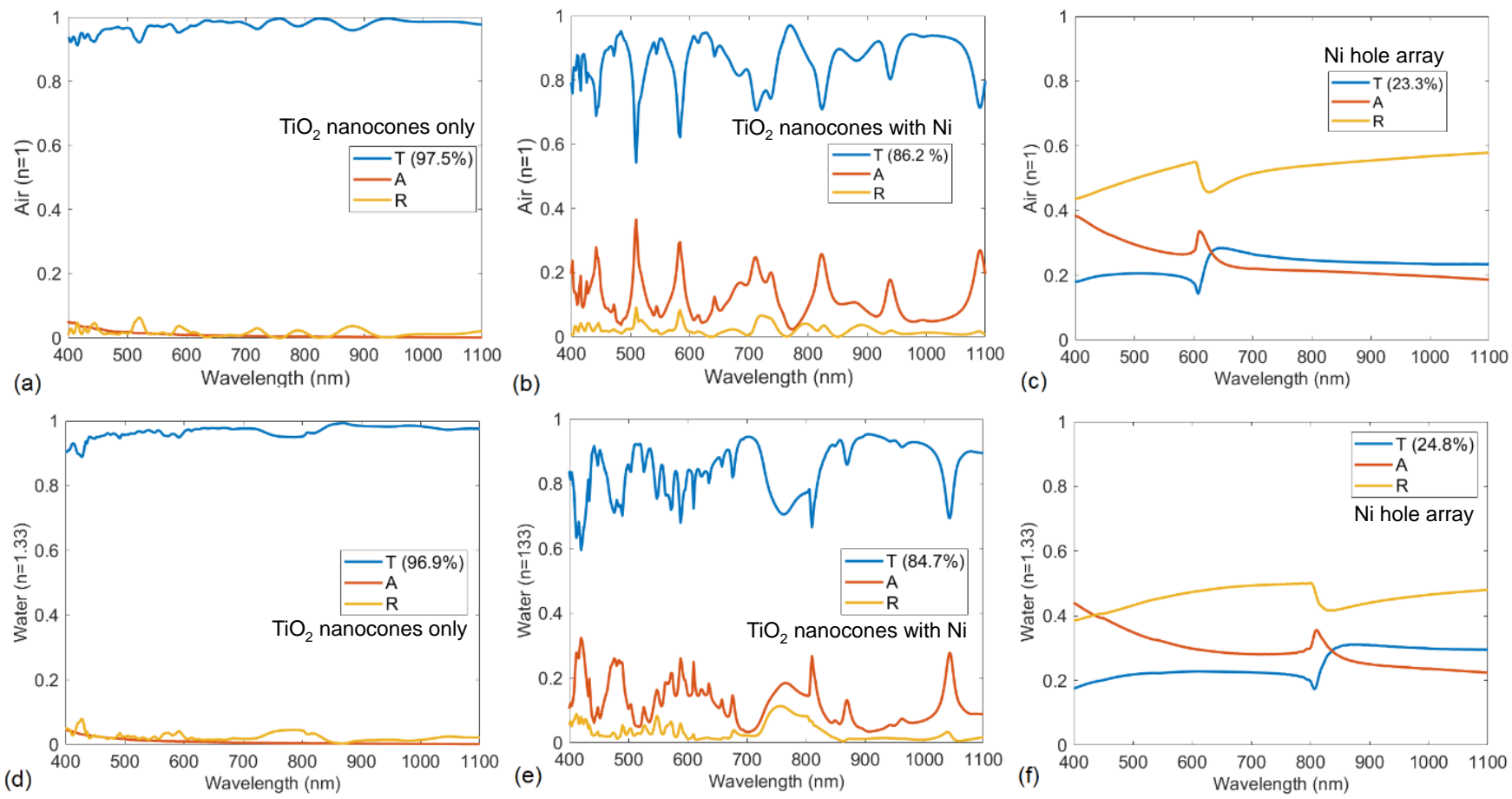

Figure 2: Simulated transmission (T), absorption (A), and reflection (R) spectra of the three configurations of the $\mathrm{TiO}_{2}$ nanocone array and Ni layer in Figure 1. (a), (b), and (c) plot the spectra in air for an array of $\mathrm{TiO}_{2}$ cones, a $\mathrm{TiO}_{2}$ cone array with $\mathrm{Ni}$, and a $\mathrm{Ni}$ hole array, respectively. (d), (e), and (f) plot the same structures but in water. The optical effects of the Si substrate are not shown.

Figure S2 plots the transmitted photon flux for each structure along with the Air Mass (AM) 1.5G solar spectrum. Using the transmitted spectral photon flux, the maximum photocurrent densities, $J_{\mathrm{ph}, \max }$, in air estimated from the simulations for a $\mathrm{Si}$ solar cell covered by either the $\mathrm{TiO}_{2}$ nanocone array, the $\mathrm{TiO}_{2}$ nanocone array with $\mathrm{Ni}$, or the Ni hole array were $J_{\mathrm{ph}, \max }=42.9 \mathrm{~mA} \mathrm{~cm}^{-}$ ${ }^{2}, 37.9 \mathrm{~mA} \mathrm{~cm}^{-2}$, and $10.9 \mathrm{~mA} \mathrm{~cm}^{-2}$ respectively. In water, the corresponding estimated simulated maximum photocurrent densities were $J_{\mathrm{ph}, \max }=41.8 \mathrm{~mA} \mathrm{~cm}{ }^{-2}, 36.5 \mathrm{~mA} \mathrm{~cm}$, and $10.7 \mathrm{~mA} \mathrm{~cm}^{-2}$, respectively. 
Figure 3 shows the simulated profiles of the electric field along the central cross section of a nanocone. Figures 3c-3f show the field profiles for wavelengths of $484 \mathrm{~nm}, 552 \mathrm{~nm}, 628 \mathrm{~nm}$, and $770 \mathrm{~nm}$, respectively, which correspond to the maxima in the transmission spectra shown in Figure $2 \mathrm{~b}$. The electric field was predominantly confined to the waveguide modes in the nanocone, with strong coupling of incident light occurring at different radii for the different wavelengths, as expected for a conical nanostructure. ${ }^{33-35}$ In the simulation, the light propagated through the nanocone and was transmitted into the Si substrate, where the field intensity decreased due to absorption by the Si. Figures $3 \mathrm{~g}-3 \mathrm{j}$ show the field profiles for wavelengths of $442 \mathrm{~nm}, 584 \mathrm{~nm}, 738$ $\mathrm{nm}$, and $940 \mathrm{~nm}$, respectively, which correspond to the minima in the transmission spectra shown in Figure $2 b$. Compared to the field profiles shown in Figures $3 c-3 f$, the profiles in Figures $3 g-3 j$ showed an increased intensity of the electric field in the space adjacent to the nanocone. The corresponding plots for transmitted light intensities $|\mathrm{E}|^{2}$ versus $\mathrm{Y}(\mu \mathrm{m})$ at the interfaces of $\mathrm{Si} / \mathrm{Ni}$ (indicated as on $\mathrm{Si}$ ) and Ni/air (indicated as on Ni) are shown in Figure S3. 


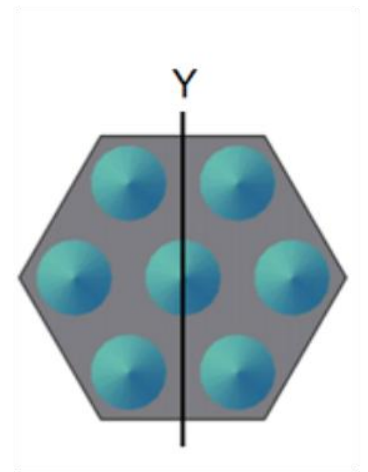

(a)

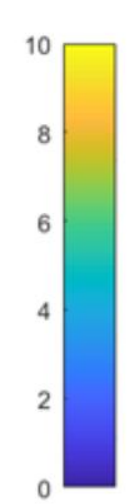

(b)

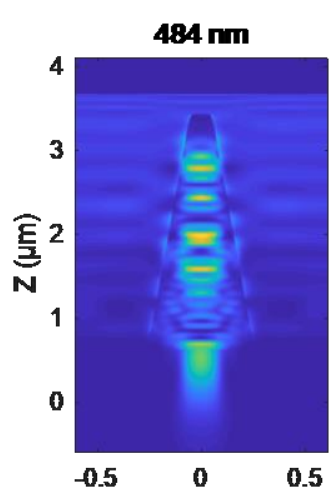

(c) $Y(\mu \mathrm{m})$

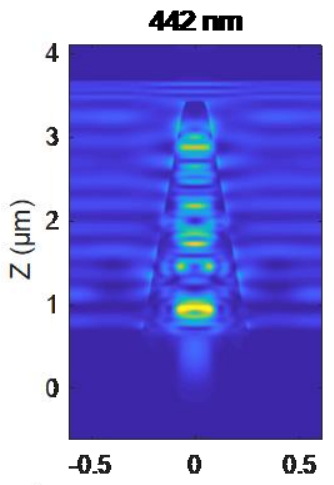

(g) $Y(\mu \mathrm{m})$

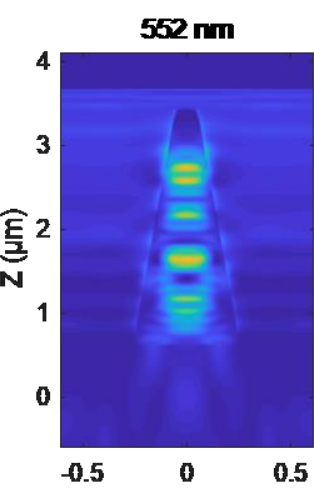

(d) $Y(\mu \mathrm{m})$

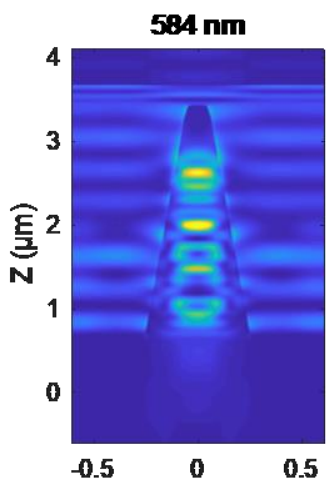

(h) $Y(\mu \mathrm{m})$

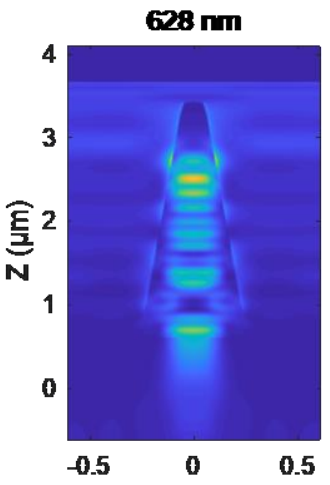

(e) $Y(\mu \mathrm{m})$

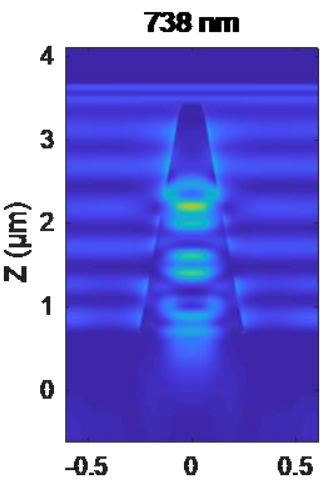

(i) $Y(\mu \mathrm{m})$

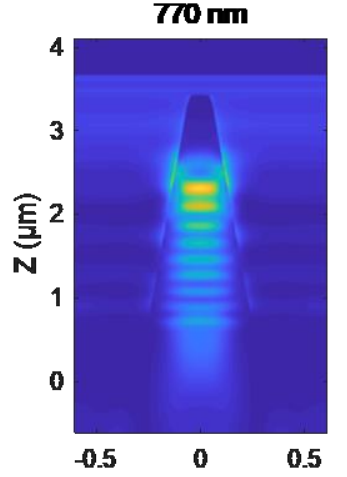

(f) $Y(\mu \mathrm{m})$

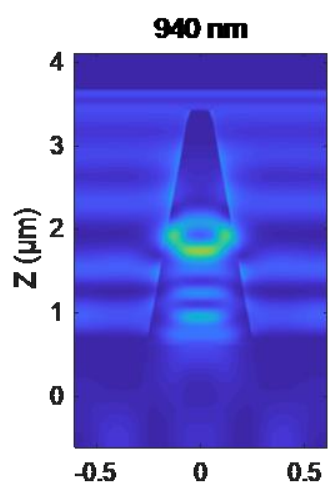

(j) $Y(\mu m)$

Figure 3: Simulated electric field profiles along the cross section of a $\mathrm{TiO}_{2}$ nanocone on a $\mathrm{Si}$ substrate. (a) Cross section and (b) scale for the relative electric field intensity for the profile plots. (c-f) Profiles for wavelengths of $484 \mathrm{~nm}, 552 \mathrm{~nm}, 628 \mathrm{~nm}$, and $770 \mathrm{~nm}$, respectively, which correspond to the maxima in the transmission spectra shown in Figure 2b. (g-j) Profiles for wavelengths of $442 \mathrm{~nm}, 584 \mathrm{~nm}, 738 \mathrm{~nm}$, and $940 \mathrm{~nm}$, respectively, which correspond to minima in the transmission spectrum in Figure 2b.

Depending on the dimensions of the nanocones and the background index of refraction, simulations indicated that the electric fields associated with some wavelengths of light were highly confined inside the $\mathrm{TiO}_{2}$ nanocone, while the electric fields associated with other wavelengths 
were only partially confined. Simulation results with varying dimensions of cones are presented in Figure S4. In contrast, the optical absorption in the Ni was enhanced for the wavelengths of light that were not completely confined within the nanocones. The wavelength-dependent variation in the confinement of the electric field within $\mathrm{TiO}_{2}$ nanocones cannot be explained using effective medium theory. Instead, wave-optic simulations showed that the nanocones acted as antennae for the incoming radiation, coupling the light to waveguide modes, and providing a route for the light to reach the underlying Si substrate even though $54 \%$ of the surface was covered by $\mathrm{Ni}$.

The optimal structures revealed by simulation were fabricated and investigated in detail. To experimentally demonstrate the enhancement in photocurrent density obtainable by utilizing $\mathrm{TiO}_{2}$ nanocone arrays, planar $\mathrm{p}^{+} \mathrm{n}$ Si homojunction photoanodes were prepared by doping n-type Si with boron (B). Briefly, electron-beam evaporation was used to deposit 5 - $10 \mathrm{~nm}$ of $\mathrm{SiO}_{2}$ over the $\mathrm{Si}$ photoanodes, prior to deposition of $2.3 \mu \mathrm{m}$ of $\mathrm{TiO}_{2}$. Electron-beam evaporation depletes the $\mathrm{TiO}_{2}$ source of oxygen and thus increases the conductivity of the resulting films, so the $5-10 \mathrm{~nm}$ thick $\mathrm{SiO}_{2}$ was deliberately incorporated to electrically isolate the $\mathrm{TiO}_{2}$ from making an electrical contact to the highly doped $\mathrm{p}^{+}-\mathrm{Si}$ surface, while minimally affecting the optical behavior. The refractive index $n, k$ of $\mathrm{TiO}_{2}$ was characterized using ellipsometry (J.A. Woollam Co. model VASE). Electron-beam lithography was used to pattern spin-coated polymethyl methacrylate (PMMA) with a hexagonal array of $100 \mathrm{~nm}$ diameter circular holes with a $700 \mathrm{~nm}$ pitch. $200 \mathrm{~nm}$ of $\mathrm{Cr}$ was evaporated onto these samples, followed by liftoff, resulting in a hexagonal array of $\mathrm{Cr}$ circles that was used as an etching mask. $\mathrm{An}_{\mathrm{SF}_{6}} / \mathrm{C}_{4} \mathrm{~F}_{8}$ etching recipe was developed to fabricate $\mathrm{TiO}_{2}$ nanocones by inductively coupled plasma reactive-ion etching (ICP-RIE). These samples were made into electrodes and $\mathrm{Ni}$ was electrodeposited between the $\mathrm{TiO}_{2}$ nanocones until $~ 300$ $\mathrm{mC} \mathrm{cm}$-2 of cathodic charge had been passed. Charge normalization to the exposed Si area between 
nanocones indicated an equivalent of an $\sim 70 \mathrm{~nm}$ thick flat Ni layer, which is slightly higher than the $50 \mathrm{~nm}$ value used in the simulations. Experimental details are included in Supporting information, and an illustration of the process flow for fabrication of the desired structures is shown in Figure S5.

Figure 4 shows scanning-electron micrographs (SEMs), before and after electrodeposition of $\mathrm{Ni}$, for samples of dry-etched $\mathrm{TiO}_{2}$ nancone arrays on planar $\mathrm{p}^{+} \mathrm{n}-\mathrm{Si}$ substrates. The EDS mappings are included in Figure $\mathrm{S} 6$. The $\mathrm{TiO}_{2}$ nanocones were $\sim 2.3 \mu \mathrm{m}$ tall and had base radii of $\sim 250 \mathrm{~nm}$. Discontinuities in the taper of the nanocones were evident, particularly near the vertex of each cone. The radii at the vertices of the nanocones were $<50 \mathrm{~nm}$. Figures $4 \mathrm{~b}$ and $4 \mathrm{~d}$ show that the Ni predominantly deposited onto the $\mathrm{Si}$ surface in the spaces between the $\mathrm{TiO}_{2}$ nanocones, as expected because the insulating 5-10 nm layer of $\mathrm{SiO}_{2}$ beneath the base of the cones should prevent electrodeposition onto the $\mathrm{TiO}_{2}$. The $\mathrm{Ni}$ layer was $\sim 70 \mathrm{~nm}$ thick as estimated based on the charge passed during electrodeposition. The SEM image of a $50 \mathrm{~nm}$ thick Ni hole array fabricated via electron-beam patterning and dry etching is shown in Figure S7.
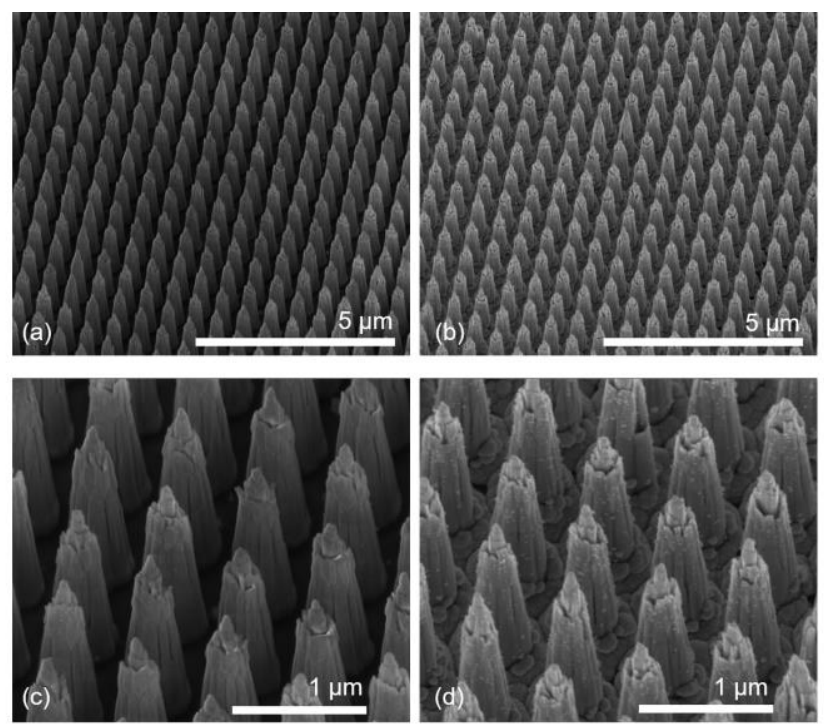
Figure 4: Scanning-electron micrographs of dry-etched $\mathrm{TiO}_{2}$ nanocones on $\mathrm{p}^{+} \mathrm{n}-\mathrm{Si}$ substrates before (a, c) and after (b, d) electrodeposition of $\mathrm{Ni}$.

Figure S8 compares the real component of the complex refractive index measured by ellipsometry for the electron-beam-evaporated amorphous $\mathrm{TiO}_{2}$ used to make nanocones in this work relative to the real component of the index of refraction of ideal rutile $\mathrm{TiO}_{2}$ tabulated in standard reference data. ${ }^{49}$ The real component of the refractive index for the electron-beamevaporated $\mathrm{TiO}_{2}$ was substantially lower $(n=2.05-2.3)$ than for the standard value $(n=2.7-3.3)$, presumably due to oxygen depletion during evaporation and the amorphous phase of the $\mathrm{TiO}_{2}$ film. Figure 5a shows the reflection, transmission, and absorption spectra calculated for $\mathrm{TiO}_{2}$ nanocones with $50 \mathrm{~nm} \mathrm{Ni}$ using the experimentally measured refractive index data for electron-beamevaporated $\mathrm{TiO}_{2}$, while Figure $5 \mathrm{~b}$ shows the simulated transmitted photon flux along with the AM 1.5G spectrum. The estimated attainable photocurrent density calculated from these revised simulations for a $\mathrm{Si}$ solar cell covered with the $\mathrm{TiO}_{2}$ nanocone array and $\mathrm{Ni}$ was $J_{\mathrm{ph}, \max }=29.8 \mathrm{~mA}$ $\mathrm{cm}^{-2}$, after correcting for losses due to reflection at the air/glass/water interfaces that are unavoidable in an electrochemical cell configuration. This estimated maximum photocurrent density $\left(J_{\mathrm{ph}, \max }=29.8 \mathrm{~mA} \mathrm{~cm}{ }^{-2}\right)$ was substantially lower than the current density that could be obtained with ideal $\mathrm{TiO}_{2}\left(J_{\mathrm{ph}, \max }=36.5 \mathrm{~mA} \mathrm{~cm}{ }^{-2}\right)$, but is still larger than the value expected for a bare, planar Si surface $\left(J_{\mathrm{ph}, \max } \sim 28 \mathrm{~mA} \mathrm{~cm}^{-2}\right)$. 

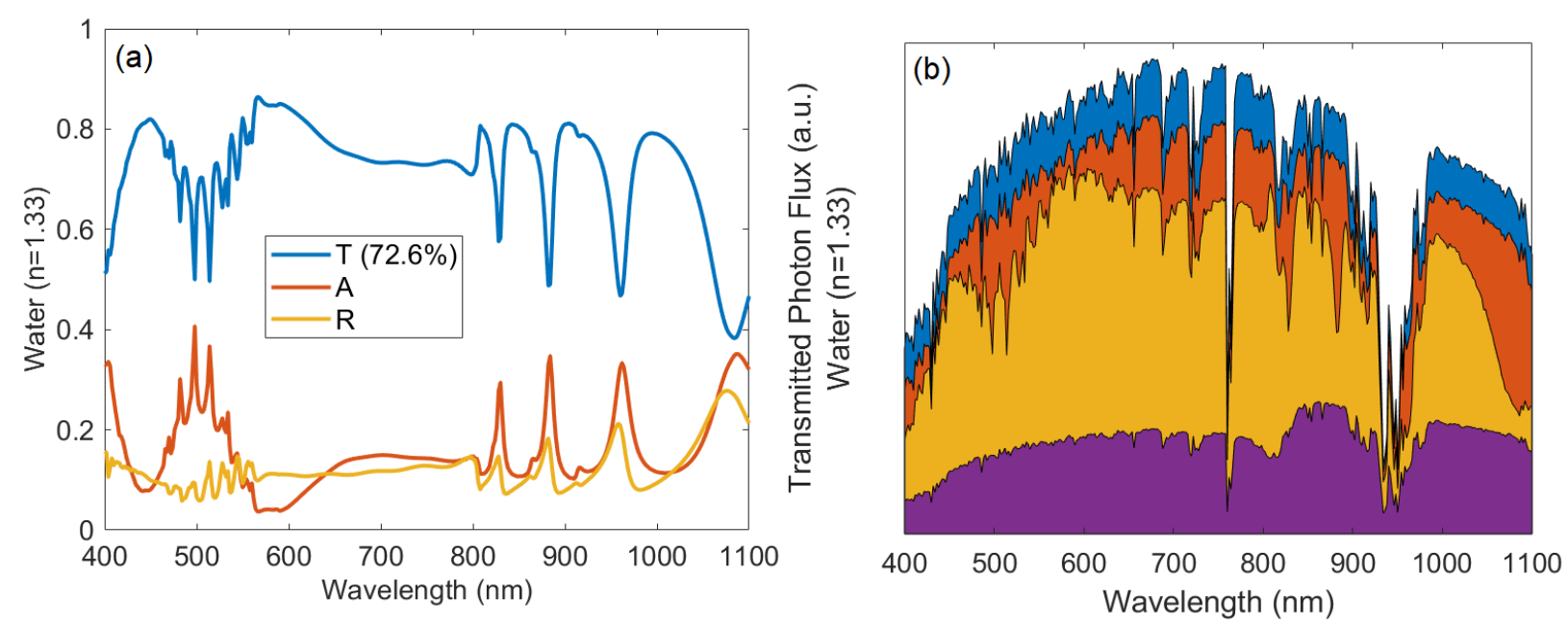

$\square$ AM 1.5G $\square$ Nanocones on $\mathrm{Si} \square$ Nanocones on Si with Ni $\square$ Ni hole array on Si

Figure 5. Transmission (T), absorption (A), and reflection (R) plots for $\mathrm{Si}$ with $\mathrm{TiO}_{2}$ nanocones and $50 \mathrm{~nm}$ thick $\mathrm{Ni}$ calculated with evaporated $\mathrm{TiO}_{2}$ refractive index data are shown in (a). (b) shows the area plot overlapped over the AM $1.5 \mathrm{G}$ spectrum for the three different cases, as shown in Fig.1, using the refractive index data for amorphous $\mathrm{TiO}_{2}$ deposited by e-beam evaporation.

Figure 6 compares simulated and experimentally measured reflectance spectra for a $\mathrm{TiO}_{2}$ nanocone array on $\mathrm{Si}$, a $\mathrm{TiO}_{2}$ nanocone array with $\mathrm{Ni}$ on $\mathrm{Si}$, and for a $50 \mathrm{~nm}$ layer of $\mathrm{Ni}$ with an array of holes. The experimental and theoretical spectra are in good mutual agreement, with certain differences readily ascribed to technical differences between the simulation and experimental conditions. For example, the simulations were performed using a coherent illumination source, whereas experimental measurements were not. Moreover, the simulations used smoothly tapering nanocones and a flat layer of $\mathrm{Ni}$, whereas the samples did not have either smoothly tapering cones or a perfectly flat Ni layer (Figure 4). 

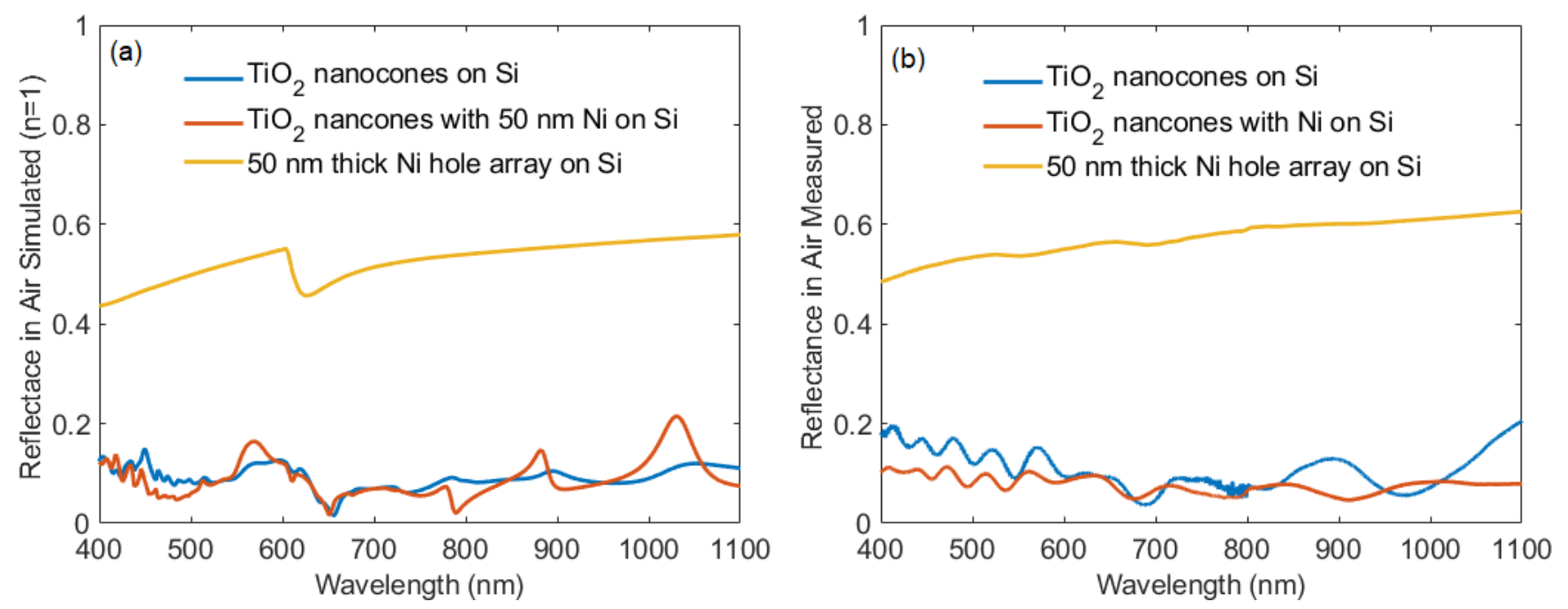

Figure 6: Reflection spectra (a) simulated and (b) measured for samples consisting of an array of $\mathrm{TiO}_{2}$ nanocones on $\mathrm{Si}$ (blue), an array of $\mathrm{TiO}_{2}$ nanocones with $\mathrm{Ni}$ on $\mathrm{Si}$ (red), an array of holes in a Ni layer on Si (yellow).

Figure 7 shows the current density versus potential behavior, in the dark and under 100 $\mathrm{mW} \mathrm{cm} \mathrm{c}^{-2}$ of simulated AM1.5 illumination, respectively, while in contact with $1.0 \mathrm{M} \mathrm{KOH}(\mathrm{aq})$, for a photoanode made from a $\mathrm{p}^{+} \mathrm{n}-\mathrm{Si}$ substrate covered with an array of $\mathrm{TiO}_{2}$ nanocones and a layer of Ni (Figures $4 \mathrm{~b}$ and 4d). The light-limited photocurrent density, obtained by subtracting the current density measured in the dark at $\sim 1 \mathrm{~V}$ vs the saturated calomel electrode (SCE) from the current density measured in the light at the same potential, was $\sim J_{\mathrm{ph}, \max }=28 \mathrm{~mA} \mathrm{~cm}{ }^{-2}$, and matched well with the value estimated $\left(J_{\mathrm{ph}, \max }=29.8 \mathrm{~mA} \mathrm{~cm}{ }^{-2}\right)$ from the simulations. The current density at the formal potential for water oxidation, $E^{\circ \prime}\left(\mathrm{O}_{2} / \mathrm{H}_{2} \mathrm{O}\right)$ was $2-7 \mathrm{~mA} \mathrm{~cm}{ }^{-2}$. The observed light-limited photocurrent density was comparable to the photocurrent density normally measured for a bare planar $\mathrm{Si}$ surface, consistent with the $\mathrm{TiO}_{2}$ nanocones serving as antireflective structures that can couple to incoming light to enable transmission of light into the Si substrate even when $54 \%$ of the Si surface was covered with $\sim 70 \mathrm{~nm}$ of $\mathrm{Ni}$. 


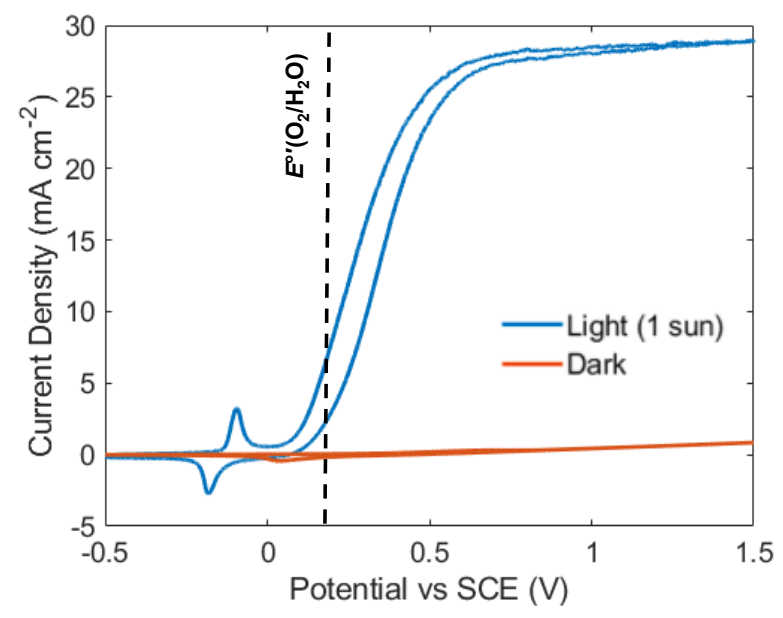

Figure 7: Current-density versus potential behavior, in the dark and under $100 \mathrm{~mW} \mathrm{~cm}^{-2}$ of simulated AM1.5 solar illumination, respectively, for a $\mathrm{p}^{+} \mathrm{n}-\mathrm{Si}$ sample covered by an array of $\mathrm{TiO}_{2}$ nanocones and $300 \mathrm{mC} \mathrm{cm} \mathrm{co}^{-2}$ of electrodeposited $\mathrm{Ni}$ while in contact with $1.0 \mathrm{M} \mathrm{KOH}(\mathrm{aq})$. The scan rate was $50 \mathrm{mV} \mathrm{s}^{-1}$.

Si photoanodes with a uniform $2 \mathrm{~nm}$ layer of $\mathrm{Ni}$ have been reported previously to exhibit a light-limited photocurrent density of $J_{\mathrm{ph}, \max } \sim 55 \mathrm{~mA} \mathrm{~cm} \mathrm{~cm}^{-2}$ under $\sim 2.25$ Suns equivalent of illumination, whereas increasing the Ni thickness to $20 \mathrm{~nm}$ reduced $J_{\mathrm{ph}, \max }$ to $\sim 32 \mathrm{~mA} \mathrm{~cm}^{-2}$. ${ }^{5}$ These results translate at 1 Sun intensity into $J_{\mathrm{ph}, \max }<25 \mathrm{~mA} \mathrm{~cm}$ for $2 \mathrm{~nm} \mathrm{Ni}$ and $<15 \mathrm{~mA} \mathrm{~cm}^{-2}$ with $20 \mathrm{~nm} \mathrm{Ni}$, whereas for comparison, the $\mathrm{p}^{+} \mathrm{n}-\mathrm{Si}$ photoanodes investigated herein exhibited $J_{\mathrm{ph}, \max } \sim 28 \mathrm{~mA} \mathrm{~cm}{ }^{-2}$. Although thick Ni catalysts are not required to lower the overpotential for water oxidation, ${ }^{51}$ the use of thick electrocatalyst layers can minimize performance degradation associated with catalyst detachment.

A wide range of alternate approaches to efficient photoelectrode performance have been demonstrated, especially when active catalysts for the desired water-splitting half-reactions are used. ${ }^{20}$ For example, $\mathrm{p}^{+} \mathrm{n}-\mathrm{Si}(111)$ photoanodes decorated with $15 \mathrm{~nm}$ thick Ni islands that covered 
$18 \%$ of the photoelectrode surface have demonstrated a light-limited current density of $20.4 \mathrm{~mA}$ $\mathrm{cm}^{-2}{ }^{51}$ Modeling has shown that the optimal efficiency of a water-splitting system using a lightfacing photocathode patterned with Pt islands covering 5\% of the optical plane closely approaches that of a system using a photocathode patterned with a hypothetical transparent catalyst with the same activity as Pt. ${ }^{52}$ Furthermore, photoanodes do not require reflective metallic catalyst coatings; indeed, $\mathrm{p}^{+} \mathrm{n}-\mathrm{Si}(100)$ photoanodes coated with $75 \mathrm{~nm}$ of sputtered $\mathrm{NiO}_{\mathrm{x}}$ have been shown to be stable for $1200 \mathrm{~h}$ of continuous oxygen evolution in contact with $1.0 \mathrm{M} \mathrm{KOH}(\mathrm{aq})$ and exhibit a light-limited photocurrent density $>30 \mathrm{~mA} \mathrm{~cm}$. The $\mathrm{TiO}_{2}$ nanocone array structure can effectively optimize light transmission and catalysis simultaneously in a variety of possible materials systems, and would be especially beneficial for chemical reactions that require very high mass loadings of catalysts, such as $\mathrm{O}_{2}$ evolution or $\mathrm{CO}_{2}$ reduction using earth-abundant electrocatalyst materials.

Dielectric nanocone arrays thus provide an additional option to a growing toolbox of strategies for directing broadband light around opaque top contacts to PV or PEC cells. The approach ought to be generally applicable for any combination of semiconductor and metal, and in principle is scalable; however, arbitrary combinations of semiconductors and metals may not be compatible with electrodeposition of the metal onto the semiconductor as used in the fabrication process described herein. Furthermore, the fabrication process developed herein for a proof-ofconcept experimental demonstration of a device that makes use of a $\mathrm{TiO}_{2}$ nanocone array for light management was complex relative to other known options for light management, such as antireflective catalyst coatings or deposition of a controlled density and diameter of catalyst islands. The value of the dielectric nanocone approach to light management can be increased by developing a simplified fabrication process and by developing synthetic methods that yield $\mathrm{TiO}_{2}$ 


\begin{abstract}
nanocones with a refractive index that approaches the index for ideal $\mathrm{TiO}_{2}$. Modeling and simulation efforts that compare attainable efficiencies for application-specific devices across relevant light-management strategies will prove valuable for identifying the strategies that are most promising for a given application.
\end{abstract}

\title{
Author Information
}

Author Contributions: †These authors contributed equally (S.Y., E.V., and W.H.C.)

Corresponding Authors: haa@caltech.edu, nslewis@caltech.edu

ORCID

Erik Verlage: 0000-0001-5940-0859

Wen-Hui Cheng: 0000-0003-3233-4606

Katherine Fountaine: 0000-0002-0414-8227

Paul Kempler: 0000-0003-3909-1790

Rebecca Saive: 0000-0001-7420-9155

Nathan S. Lewis: 0000-0001-5245-0538

Harry A. Atwater: 0000-0001-9435-0201

Note: The authors declare no competing financial interest

\section{Acknowledgments}

The fabrication and assessment of photoanodes for the oxygen-evolution reaction was supported through the Office of Science of the U. S. Department of Energy under Award No. DE-SC0004993 for the Joint Center for Artificial Photosynthesis and used facilities of the Kavli Nanoscience 
Institute at Caltech, a DOE Energy Innovation Hub; the development of simulations was supported by the National Science Foundation under award No. EEC-1041895.

Supporting Information Available: Methods, simulated spectra of the $\mathrm{TiO}_{2}$ film, simulated transmitted spectral photon flux, lateral distribution of transmitted light intensities, dimension variation effect on transmission, process flow diagram, EDS mapping of the $\mathrm{TiO}_{2}$ nanocones with Ni sample, SEM image of the Ni hole array, and refractive index for $\mathrm{TiO}_{2}$. This material is available free of charge via the Internet at http://pubs.acs.org.

\section{References}

(1) Holman, Z.; Boccard, M. In Photovoltaic Solar Energy: From Fundamentals to Applications; John Wiley \& Sons, Ltd.: Hoboken, New Jersey, 2016.

(2) Manzoor, S.; Yu, Z. J.; Ali, A.; Ali, W.; Bush, K. A.; Palmstrom, A. F.; Bent, S. F.; McGehee, M. D.; Holman, Z. C. Sol. Energy Mater. Sol. Cells 2017, 173, 59.

(3) Haug, F. J.; Ballif, C. Energy Environ. Sci. 2015, 8, 824.

(4) Schmid, M. Semicond. Sci. Technol. 2017, 32, 043003.

(5) Peer, A.; Biswas, R.; Park, J.-M.; Shinar, R.; Shinar, J. Opt. Express 2017, 25, 10704.

(6) Walter, M. G.; Warren, E. L.; McKone, J. R.; Boettcher, S. W.; Mi, Q.; Santori, E. A.; Lewis, N. S. Chem. Rev. 2010, 110, 6446.

(7) Hu, S.; Xiang, C.; Haussener, S.; Berger, A. D.; Lewis, N. S. Energy Environ. Sci. 2013, 6, 2984.

(8) Fountaine, K. T.; Lewerenz, H. J.; Atwater, H. A. Nat. Commun. 2016, 7, 13706.

(9) Raut, H. K.; Ganesh, V. A.; Nair, A. S.; Ramakrishna, S. Energy Environ. Sci. 2011, 4, 3779.

(10) Krč, J.; Smole, F.; Topič, M. Prog. Photovoltaics: Res. Appl. 2003, 11, 429.

(11) Campbell, P.; Green, M. A. J. Appl. Phys. 1987, 62, 243.

(12) Yablonovitch, E.; Cody, G. D. IEEE Trans. Electron Devices 1982, 29, 300.

(13) Cho, S. J.; An, T.; Lim, G. Chem. Commun. 2014, 50, 15710.

(14) Brongersma, M. L.; Cui, Y.; Fan, S. Nat. Mater. 2014, 13, 451.

(15) Mokkapati, S.; Catchpole, K. R. J. Appl. Phys. 2012, 112, 101101.

(16) Wilson, G. AIP Conf. Proc. 2018, 1924, 020003.

(17) Verlage, E.; Hu, S.; Liu, R.; Jones, R. J. R.; Sun, K.; Xiang, C.; Lewis, N. S.; Atwater, H. A. Energy Environ. Sci. 2015, 8, 3166.

(18) Zhou, X.; Liu, R.; Sun, K.; Chen, Y.; Verlage, E.; Francis, S. A.; Lewis, N. S.; Xiang, C. ACS Energy Lett. 2016, 1, 764. 
(19) Cheng, W.-H.; Richter, M. H.; May, M. M.; Ohlmann, J.; Lackner, D.; Dimroth, F.; Hannappel, T.; Atwater, H. A.; Lewerenz, H.-J. ACS Energy Lett. 2018, 3, 1795.

(20) Sun, K.; Moreno-Hernandez, I. A.; Schmidt, W. C.; Zhou, X.; Crompton, J. C.; Liu, R.; Saadi, F. H.; Chen, Y.; Papadantonakis, K. M.; Lewis, N. S. Energy Environ. Sci. 2017, $10,987$.

(21) Yoshikawa, K.; Kawasaki, H.; Yoshida, W.; Irie, T.; Konishi, K.; Nakano, K.; Uto, T.; Adachi, D.; Kanematsu, M.; Uzu, H.; Yamamoto, K. Nat. Energy 2017, 2, 17032.

(22) Lammert, M. D.; Schwartz, R. J. IEEE Trans. Electron Devices 1977, $24,337$.

(23) Spitzer, M. B.; Fan, J. C. C. Sol. Cells 1990, 29, 183.

(24) Garnett, E.; Yang, P. D. Nano Lett. 2010, 10, 1082.

(25) Tian, B. Z.; Zheng, X. L.; Kempa, T. J.; Fang, Y.; Yu, N. F.; Yu, G. H.; Huang, J. L.; Lieber, C. M. Nature 2007, 449, 885.

(26) Wallentin, J.; Anttu, N.; Asoli, D.; Huffman, M.; Aberg, I.; Magnusson, M. H.; Siefer, G.; FussKailuweit, P.; Dimroth, F.; Witzigmann, B.; Xu, H. Q.; Samuelson, L.; Deppert, K.; Borgstrom, M. T. Science 2013, 339, 1057.

(27) Mavrokefalos, A.; Han, S. E.; Yerci, S.; Branham, M. S.; Chen, G. Nano Lett. 2012, 12, 2792.

(28) Zhu, J.; Hsu, C. M.; Yu, Z. F.; Fan, S. H.; Cui, Y. Nano Letters 2010, 10, 1979.

(29) Yao, Y.; Yao, J.; Narasimhan, V. K.; Ruan, Z. C.; Xie, C.; Fan, S. H.; Cui, Y. Nat. Commun. 2012, 3.

(30) Kapadia, R.; Fan, Z. Y.; Takei, K.; Javey, A. Nano Energy 2012, 1, 132.

(31) Narasimhan, V. K.; Hymel, T. M.; Lai, R. A.; Cui, Y. ACS Nano 2015, 9, 10590.

(32) Jeong, S.; Garnett, E. C.; Wang, S.; Yu, Z. G.; Fan, S. H.; Brongersma, M. L.; McGehee, M. D.; Cui, Y. Nano Lett. 2012, 12, 2971.

(33) Yalamanchili, S.; Emmer, H. S.; Fountaine, K. T.; Chen, C. T.; Lewis, N. S.; Atwater, H. A. ACS Photonics 2016, 3, 1854.

(34) Fountaine, K. T.; Cheng, W.-H.; Bukowsky, C. R.; Atwater, H. A. ACS Photonics 2016, 3, 1826.

(35) Fountaine, K. T.; Kendall, C. G.; Atwater, H. A. Opt. Express 2014, 22, A930.

(36) Grandidier, J.; Callahan, D. M.; Munday, J. N.; Atwater, H. A. Adv. Mater. 2011, 23, 1272.

(37) Choy, J. T.; Bradley, J. D. B.; Deotare, P. B.; Burgess, I. B.; Evans, C. C.; Mazur, E.; Lončar, M. Opt. Lett. 2012, 37, 539.

(38) Evans, C. C.; Liu, C.; Suntivich, J. Opt. Express 2015, 23, 11160.

(39) Evans, C. C.; Shtyrkova, K.; Bradley, J. D. B.; Reshef, O.; Ippen, E.; Mazur, E. Opt. Express 2013, 21, 18582.

(40) Evans, C. C.; Shtyrkova, K.; Reshef, O.; Moebius, M.; Bradley, J. D. B.; Griesse-Nascimento, S.; Ippen, E.; Mazur, E. Opt. Express 2015, 23, 7832.

(41) Guan, X.; Hu, H.; Oxenløwe, L. K.; Frandsen, L. H. Opt. Express 2018, 26, 1055.

(42) Bradley, J. D. B.; Evans, C. C.; Choy, J. T.; Reshef, O.; Deotare, P. B.; Parsy, F.; Phillips, K. C.; Lončar, M.; Mazur, E. Opt. Express 2012, 20, 23821.

(43) Sun, K.; Kuang, Y.; Verlage, E.; Brunschwig, B. S.; Tu, C. W.; Lewis, N. S. Adv. Energy Mater. 2015, $5,1402276$.

(44) Hu, S.; Shaner, M. R.; Beardslee, J. A.; Lichterman, M.; Brunschwig, B. S.; Lewis, N. S. Science 2014, 344, 1005.

(45) Lichterman, M. F.; Carim, A. I.; McDowell, M. T.; Hu, S.; Gray, H. B.; Brunschwig, B. S.; Lewis, N. S. Energy Environ. Sci. 2014, 7, 3334.

(46) McDowell, M. T.; Lichterman, M. F.; Carim, A. I.; Liu, R.; Hu, S.; Brunschwig, B. S.; Lewis, N. S. ACS Appl. Mater. Interfaces 2015, 7, 15189. 
(47) McDowell, M. T.; Lichterman, M. F.; Spurgeon, J. M.; Hu, S.; Sharp, I. D.; Brunschwig, B. S.; Lewis, N. S. J. Phys. Chem. C 2014, 118, 19618.

(48) Shaner, M. R.; Hu, S.; Sun, K.; Lewis, N. S. Energy Environ. Sci. 2015, 8, 203.

(49) Siklitsky, V. Available: http://www.ioffe.rssi.ru/SVA/NSM 2001.

(50) Kenney, M. J.; Gong, M.; Li, Y.; Wu, J. Z.; Feng, J.; Lanza, M.; Dai, H. Science 2013, 342, 836.

(51) Sun, K.; Ritzert, Nicole L.; John, J.; Tan, H.; Hale, W. G.; Jiang, J.; Moreno-Hernandez, I.; Papadantonakis, K. M.; Moffat, T. P.; Brunschwig, B. S.; Lewis, N. S. Sustainable Energy Fuels 2018, 2, 983.

(52) Chen, Y.; Sun, K.; Audesirk, H.; Xiang, C.; Lewis, N. S. Energy Environ. Sci. 2015, 8, 1736. 